\title{
Performance Improvement of Air Path Dynamics in Diesel Engines Using LQR/LQG Optimal \& Switching Control Techniques
}

\author{
Shashidhar S Gokhale, Yathisha L, S Patil Kulkarni
}

\begin{abstract}
Conceptual: The modern-day chalenge for the manipulate framework network is to enhance the exhibition of the kingdom elements associated enormous all spherical manner of diesel cars. The automobile enterprise is utilising Exhaust fuel Recirculation (EGR), Variable Geometry Turbine (VGT) and Fuelling has manipulate contributions of air elements. subsequently, on this paper analyses are executed whilst the framework is uncovered to deterministic and arbitrary commotions through structuring the controller utilizing Linear Quadratic Gaussian (LQG). The proposed controller is contrasted and Linear Quadratic Regulator (LQR) and Later, converting among LQG controllers is likewise proposed to approve the effects without changing.
\end{abstract}

\section{ADVENT}

Air manner is applied in the diesel cars since it offers a natural air critical oxygen into the chambers. the existing air way elements related in automobile frameworks running over scope of operating situations with unsettling impacts, balancing out the framework, lessening the overshoots for country factors is a massive take a look at. This has been an area of intense research for car employer in current a long term. control framework community has ben the use of Exhaust gas Recirculation (EGR), Variable Geometry Turbine (VGT) and Fuelling has manipulate contributions of air elements because of this. A short writing examine of later works on this region of studies exhibited under is a wonderful notion for the proposed paintings.

(Mike Huang et al. 2016) proposed a version prescient manipulate (MPC) for diesel air manner factors and the consequences demonstrates that zero-stability enduring country following is executed. (Javad Mohammadpour and Karolos Grigoriadis et al. 2010) offers the straight away parameter moving (LPV) decoupling manage and a prefilter to improve the following execution crucial all round manner of Diesel vehicles displayed as a semi LPV framework. duplicate outcomes show the important development finished via the proposed controller. The creators in (Stephan Zentner and Erika et al. 2014), planned the manage technique to address go-couplings of the framework and the results are contrasted and an regular controller of equivalent tuning. For

Revised Version Manuscript Received on 10 September, 2019.

Shashidhar S Gokhale, Research Scholar, JSSRF, Associate Profesor, Dept. of ECE, ATME College Of Engineering, Mysuru, Karnataka, India(Email: shashisg@gmail.com)

Yathisha L, Associate Profesor, Dept. of ECE, ATME College Of Engineering, Mysuru, Karnataka, India (Email: yathisha.171@gmail.com)

S Patil Kulkarni, Professsor, Dept. of ECE, JSSRF \& JSSSTU, Mysuru, Karnataka, India (Email: pk.sudarshan@gmail.com) the examination, a solitary diploma turbocharged diesel motor geared up with a VGT and HP EGR become utilized.(Dezong Zhao, Cunjia Liu and Richard Stobart et al. 2013) addresses the air way guideline in turbocharged diesel motors making use of an unequivocal version prescient control (EMPC) technique and duplicate consequences basically improves the following execution of the fumes outflow factors towards the decentralized single-enter unmarried-yield (SISO) control approach. The brief feedforward manipulate framework in a robotized course for the diesel motor is proposed by way of the use of (Giorgio Mancini and Jonas Asprion et al. 2014). The proposed approach is actualized on a true motor and trial consequences are displayed along the development of the device.

(Fereidoon Shabaninia et al. 2012) presents a outstanding LQG/LTR manipulate technique for a gas turbine and the assignment outcomes are contrasted and PID controller. The outcomes uncovers that the proposed controller has exquisite execution. (Mohamed Guermouche and Sofiane Ahmed Ali et al. 2014), built up a higher request sliding mode control machine for the inward ignition motor air manner and the workout effects of air way motor version indicates first rate consequences underneath actuator flaws situations even in the sight of parametric vulnerabilities. In (Peter Langthaler and Luigi del Re et al.2014) the creators thinks about various active prescient control methodologies completed to a Diesel motor airpath and the outcomes presume that the sturdy model Predictive control (RMPC) gadget offers progressively complex system to the standard motor manage strategies which are tuned by way of utility engineers. (Zhijia Yang et al. 2014) investigates creative manage systems plan for a rock strong Caterpillar C6.6 diesel motor and the replica results uncovers that the proposed manage form gives higher execution to the framework damping.

within the existing paintings, deterministic and arbitrary commotions are exposed to the air manner factors and settled utilising LQG controller and the effects are contrasted and LQR controller. similarly, a keen changing manage technique is proposed to replace among LQG controllers with the end purpose that the advancement is finished in stages: changing determine that upgrades yield strength and person high-quality controllers among which replacing takes place. 


\section{PERFORMANCE IMPROVEMENT OF AIR PATH DYNAMICS IN DIESEL ENGINES USING LQR/LQG OPTIMAL \& SWITCHING CONTROL TECHNIQUES}

\section{AIR PATH DYNAMICS}

The 0.33 order nonlinear imply-price model parametrized for low and medium speed load factors, which covers the new european pressure Cycle (NEDC), it became proposed via (Jung M et al. 2003) for robust control functions.

After, linearization the Linear Time Invariant (LTI) model can be written in the nation space as:

$\Delta \dot{x}=A \Delta x+B \Delta u$

$\Delta y=C \Delta x+D \Delta u$

where, $\Delta x=x-x_{0}, \Delta u=u-u_{0}$, and $\Delta y=y-y_{0}$; $A, B, C, D$ are the coefficient matrices of the state space model. The Numerical values of $A \& B$ matrices used for the experiment is as follows:

$$
\begin{gathered}
A=\left[\begin{array}{lll}
-5.2643 & 4.7316 & 28.5021 \\
50.7697 & -156.9827 & 0 \\
0 & 0.4287 & -9.0909
\end{array}\right] \\
B=\left[\begin{array}{lll}
1.6111 * 10^{9} & 0 & 0 \\
1.5720 * 10^{1} 0 & 8.3514 * 10^{4} & 1.46083 * 10^{8} \\
0 & -141.6484 & 0
\end{array}\right]
\end{gathered}
$$

Table 1: States and Input/Output variables of the system

\begin{tabular}{|l|c|c|}
\multicolumn{1}{|c|}{ Variable } & Notation & Function \\
\hline EGR-Actuator effective area & $\Delta A_{\text {egr }}$ & Input \\
\hline VGT-Actuator position & $\Delta x_{\text {vgt }}$ & Input \\
\hline Engine speed & $\Delta N$ & Disturbance \\
\hline $\begin{array}{l}\text { Intake manifold pressure } \\
\left(p_{i}\right)\end{array}$ & $\Delta x_{1}$ & State variable 1 \\
\hline $\begin{array}{l}\text { Exhaust manifold pressure } \\
\left(p_{x}\right)\end{array}$ & $\Delta x_{2}$ & State variable 2 \\
\hline \multicolumn{1}{|c|}{ Turbine power $\left(P_{c}\right)$} & $\Delta x_{3}$ & State variable 3 \\
\hline
\end{tabular}

\section{FOREMOST CONTROL THEORY}

The orderly technique for locating a manage regulation $\mathrm{u}=-\mathrm{Kx}$, in which the close framework has a gurantee of stability with some enhancement completed most of the manipulate cost and yield execution is alluded to as perfect control. For the ebb and float check out, the upgraded enter controllers are gotten from the LQR and whilst the framework is exposed to unsettling affects, the controllers are gotten from LQG. For, the reason of fulfillment LQR and LQG manage strategies are clarified fast inside the accompanying regions:

\subsection{Linear Quadratic Regulator manage}

The exhibition file can be restricted with the resource of desigining the enter controlers with the identical vintage device of LQR (Anderson et al., 2007); Yathisha et al., 2013).

recollect a framework with

$\dot{x}(t)=A x(t)+B u(t)$

$y(t)=C x(t)$

The input $u(t)$ is expressed as $r(t)-K x(t)$, where $r(t)$ is the reference input and $K$ is the feedback gain, also called the control law.

The closed loop system is given by

$$
\dot{x}(t)=(A-B K) x(t)
$$

The most systematic and popular method to find $K$ is to minimize the quadratic performance index

$$
J=\int_{0}^{\infty}\left(x^{T} Q x+u^{T} R u\right) d t
$$

where $\mathrm{Q}$ and $\mathrm{R}$ are the positive-definite Hermitian or real symmetric matrix.
From the above equations

$K=-R^{-1} B^{T} P$

and hence the control law is

$u(t)=-K x(t)=-R^{-1} B^{T} P x(t)$

in which $P$ must satisfy reduced Riccati equation:

$P A+A^{T} P-P B R^{-1}+B^{T} P+Q=0$

The LQR trademark lets in you to pick two parameters, $\mathrm{R}$ and $\mathrm{Q}$, at the best approach to adjust the ${ }_{1}$ general noteworthiness of the enter and kingdom inside the 2 charge work that you are endeavoring to enhance.

\subsection{Linear Quadratic Gaussian oversee}

On the off chance that a controller is structured utilizing the LQR, and the eyewitness is planned utilizing Kalman get out, the resulting gadget is called LQG oversee.

The Kalman channel out procedure gives the way for planning spectator benefits for Multi enter-Multi Output (MIMO) structures, with the end goal that the structured onlooker increase is guaranteed to be best even inside the nearness of commotion sign. Remember a plant with LTI kingdom territory outline given as

$$
\begin{aligned}
& \dot{x}(t)=A x(t)+B u(t)+w(t) \\
& y(t)=C x(t)+D u(t)+v(t)
\end{aligned}
$$

Where, $w(t)$ is the process noise and $v(t)$ is the measurement noise.

$$
u(t)=-K \hat{x}(t)
$$

The Kalman filter is an optimal estimator when dealing with Gaussian white noise. Specifically, it minimizes the asymptotic covariance of the estimation error $e_{0}=x-\hat{x}$, given by

$$
\lim _{t \rightarrow \infty} E\left((x-\hat{x})(x-\hat{x})^{\prime}\right)
$$

The goal is to regulate the plant output $y$ to be near zero. The state equation of the Kalman filter can be written as (Azad et al., 2013; Tripathy et al., 2010):

$$
\dot{\hat{x}}=A \hat{x}+B u+L(y-C \hat{x}-D u)
$$

For the time invariant problem, the following algebraic Riccati equation provides the optimal covariance matrix $M$, (Yousef et al., 2008):

$$
A M+M A^{T}-M C^{T} V^{-1} C M+B W B^{T}=0 .
$$

The algebraic Riccati equation can be solved using the specified Kalman filter MATLAB command lqe (linear quadratic estimator). The Kalman filter optimal gain $L$ is given by

$[L, M, E]=\operatorname{lqe}(A, B, C, W, V)$

where

$\mathrm{L}$ is the decrease back Kalman channel best addition,

$\mathrm{M}$ is the lower back answer for the arithmetical Riccati condition and,

$\mathrm{E}$ is a vector containing the eigenvalues of the 3Kalman channel (eigenvalues of A-LC).

At prolonged last, turning into a member of the independently planned perfect LQR (k) controller and Kalman channel into an excellent compensator (LQG) as regarded in Fig. 2, the new subsystem creates the statistics 
vector, $u(t)$ in view of the evaluated country vector, $x^{\gamma}(t)$, in preference to the genuine nation vector $\mathrm{x}(\mathrm{t})$ and the planned yield $\mathrm{y}(\mathrm{t})$.

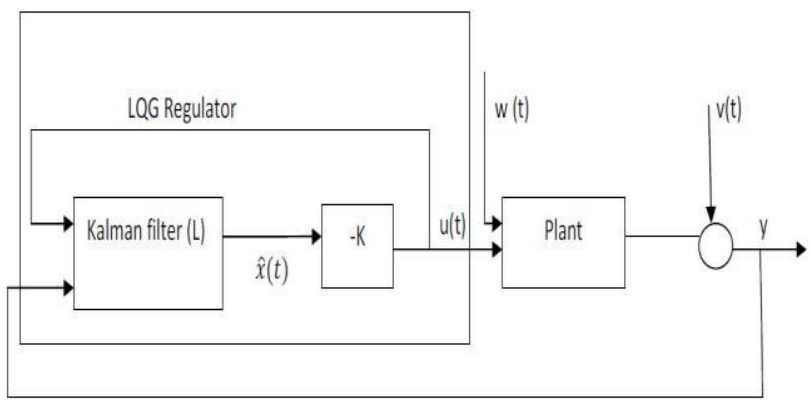

Figure 1: Block Diagram of Optimal LQG compensator

\section{SWITCHED LINEAR MANAGE CONCEPT}

Exchanged frameworks are made from a meeting of sub-frameworks guided by way of manner of an replacing law that administers the alternate amongst those subsystems. In LTI frameworks, by using using splendidly changing between numerous manipulate structures depending upon the country esteem, progressed execution may be finished contrasted with individual control structure.

An exchanged direct framework model is as in line with the subsequent:

$$
\dot{x}(t)=A_{\sigma(t)} x(t)
$$

The switching signal $\sigma(t)$ indicates

$$
\begin{aligned}
& \dot{x}(t)=A_{1} x(t)=i f, \quad \sigma(t)=1, \\
& =A_{2} x(t)=i f, \quad \sigma(t)=2,
\end{aligned}
$$

where

$$
\begin{aligned}
& A_{1}=A-B K_{1} \\
& A_{2}=A-K_{2} .
\end{aligned}
$$

the 2 improved complaint controller profits $\mathrm{K} \_1$ and $\mathrm{K} \_2$ for the close circle frameworks A_1 and A_2 are gotten from LQR through tuning the weighting networks for the ebb and waft look at.

\section{four.1 Switching manipulate set of rules}

An changing calculation that limits yield energy and furthermore established to balance out is brought in Aravena et al. (2006); Yathisha e. Al. $(2015 ; 2017 ; 2018)$ and seemed in Fig. 2 .

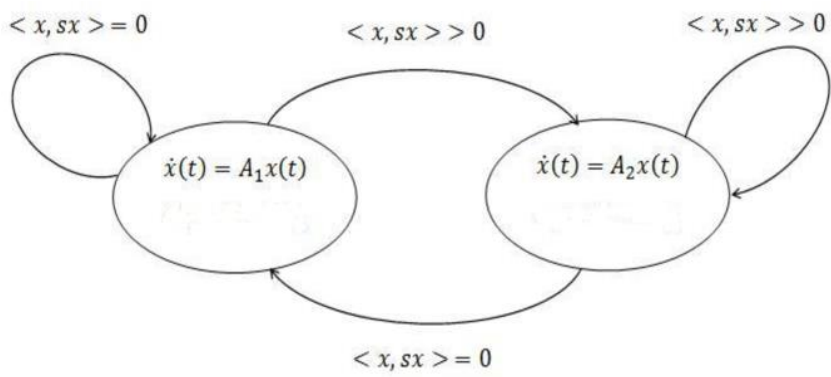

Figure 2: State diagram of switching algorithm between two closed-loop systems.

Steps are as follow:

1. Initialize the two closed loop systems $A_{1} \& A_{2}$.

2. Determine $T_{0}$ by solving the algebraic Lyapunov Equation: $A_{1}^{T} T_{0}+T_{0} A_{1}=-C^{T} C$.
3. Define the switching matrix as:

$$
S=-\left(A_{2}^{T} T_{0}+T_{0} A_{2}+C^{T} C\right) .
$$

4. Apply the switching rule:

$\sigma(t)=2$ if $\langle x, S x>>0=1$ otherwise.

4.2 Stability of Switching Strategy

Proof:

Consider the matrix pencil equation,

$A_{\sigma}=\gamma A_{2}+(1-\gamma) A_{1}$

such that when $x^{\prime} S x>0, \gamma=1$ and system matrix is $A_{2}$, otherwise $\gamma=0$ and system matrix is $A_{1}$.

Consider the positive definite function

$V(x)=\prec x, T_{0} x>$

For Lyapunov stability consider

$$
\begin{aligned}
& \dot{V}=\frac{d<x, T_{0} x>}{d t} \\
& =<x,\left(A_{\sigma}^{T} T_{0}+T_{0} A_{\sigma}\right) x> \\
& =<x, A_{\sigma}^{T} T_{0} x>+\prec x, T_{0} A_{\sigma} x>
\end{aligned}
$$

Substitute the value of $A_{\sigma}$ from Eq. 18 and solving the above equation leads to

$$
\begin{aligned}
\dot{V}=\gamma \prec x,\left(A_{2}^{T} T_{0}+T_{0} A_{2}\right) x> & \\
& +(1-\gamma) \prec x,\left(A_{1}^{T} T_{0}+T_{0} A_{1}\right) x>
\end{aligned}
$$

$$
\begin{aligned}
& \text { Let, } S(x)=-\prec x,\left(A_{2}^{T} T_{0}+T_{0} A_{2}+C^{T} C\right) x>\underset{\text { (17) }}{\text { and }} \\
& A_{1}^{T} T_{0}+T_{0} A_{1}=-C^{T} C
\end{aligned}
$$

Than,

From the above Eq. 24, If the system is observable, it is well known that the function $-\prec x, C^{T} C x>$ is non positive and cannot be zero over any time interval. When $S(x) \leq 0$, $\gamma=0$, the first term a single lyapunov function $V(x)$ such that $\dot{V}$ is negative. Hence, state that the system is asymptotically stable.

\section{EXPERIMENTAL SET-UP}

The proposed novel manipulate strategies for the control inputs VGT (B_2) and Fuelling (B_3) is explored by using the use of thinking about the accompanying instances:

Case I:

LQR and LQG Controllers are meant for the manipulate input VGT (B_2). The criticism controller and spectator profits for the united states of america factors consumption complex weight (p_i) and Turbine control (p_x) deviations are as consistent with the subsequent:

$$
\begin{aligned}
& K\left(p_{i}\right)=\left[\begin{array}{llll}
0.9886 & 0.0089 & 0.0644
\end{array}\right] \\
& K\left(p_{x}\right)=\left[\begin{array}{llll}
0.0026 & 0.0026 & 0.7668
\end{array}\right]
\end{aligned}
$$

$L\left(p_{i}\right)=$

$\left[1.207 * 10^{5} \quad 1.5555 * 10^{9} \quad-2.6337 * 10^{6}\right.$ 


\section{PERFORMANCE IMPROVEMENT OF AIR PATH DYNAMICS IN DIESEL ENGINES USING LQR/LQG OPTIMAL \& SWITCHING CONTROL TECHNIQUES}

$L\left(p_{x}\right)$

$=\left[\begin{array}{lll}5.5416 * 10^{7} & -3.4898 * 10^{8} & 2.6451 * 10^{6}\end{array}\right.$

Case II:

LQR and LQG Controllers are intended for the control enter Fuelling (B_3). The criticism controller and eyewitness gains for the kingdom factors utilization complex strain $\left(\mathrm{p} \_\mathrm{i}\right)$ and Turbine quality $\left(\mathrm{p}_{-} \mathrm{x}\right)$ deviations are as per the following:

$$
\begin{aligned}
& K\left(p_{i}\right)=\left[\begin{array}{lll}
0.99997 & 2.5343 * 10^{-4} & 0.0015 \\
K\left(p_{x}\right) & & \\
=\left[3.4753 * 10^{-7}\right. & 7.5482 * 10^{-5} & 0.9984
\end{array}\right.
\end{aligned}
$$$$
L\left(p_{i}\right)
$$$$
=\left[\begin{array}{lll}
2.125 * 10^{8} & 4.7718 * 10^{15} & 1.9253 * 10^{7}
\end{array}\right.
$$

$=\left[\begin{array}{lll}7.0597 * 10^{8} & 4.7718 * 10^{15} & 6.3964 * 10^{7}\end{array}\right.$

Case III:

Switching control techniques among LQG controllers are actualized for the manipulate input VGT (B_2). The numerical decided estimations of improved complaint LQR controller increases vital $\left(\mathrm{K} \_\alpha\right)$ and auxiliary $\left(\mathrm{K} \_\beta\right)$ alongside the exchanging lattices for the nation factors intake complicated weight $\left(\mathrm{p}_{-} \mathrm{i}\right)$ and Turbine manipulate $\left(\mathrm{p}_{-} \mathrm{x}\right)$ deviations are as in step with the following:

$$
\begin{aligned}
& K_{\alpha}\left(p_{i}\right)=\left[\begin{array}{llll}
0.9886 & 0.0089 & 0.0644
\end{array}\right] \\
& K_{\beta}\left(p_{i}\right)=\left[\begin{array}{llll}
3.1417 & 0.0172 & 0.1141
\end{array}\right] \\
& S\left(p_{i}\right)=\left[\begin{array}{llll}
2.1405 & 0.0098 & 0.0589 \\
0.0098 & 4.3462 * 10^{-5} & 2.6214 * 10^{-4} \\
0.0589 & 2.6214 * 10^{-4} & 0.0016
\end{array}\right] \\
& K_{\alpha}\left(p_{x}\right)=\left[\begin{array}{llll}
0.0026 & 0.0026 & 0.7668
\end{array}\right] \\
& K_{\beta}\left(p_{x}\right)=\left[\begin{array}{llll}
0.0059 & 0.0091 & 2.5682 &
\end{array}\right] \\
& S\left(p_{x}\right)=\left[\begin{array}{llll}
5.3459 * 10^{-6} & 1.0092 * 10^{-5} & 0.0028 \\
1.0092 * 10^{-5} & 1.9026 * 10^{-5} & 0.0056 \\
0.0028 & 0.0053 & 1.5015
\end{array}\right]
\end{aligned}
$$

Case IV:

Switching manipulate strategies among LQG controllers are achieved for the control enter Fuelling (B_3). The numerical calculated values of two optimized feedback LQR controller earnings number one $\left(\mathrm{K} \_\alpha\right)$ and secondary $\left(\mathrm{K} \_\beta\right)$ collectively with the switching matrices for the nation variables intake manifold stress (p_i) and Turbine electricity (p_x) deviations are as follows:

$$
\begin{gathered}
K_{\alpha}\left(p_{i}\right)=\left[\begin{array}{lll}
0.99997 & 2.5343 * 10^{-4} & 0.0015
\end{array}\right] \\
K_{\beta}\left(p_{i}\right)=\left[\begin{array}{lll}
3.1618 & 4.5151 * 10^{-4} & 0.0027
\end{array}\right] \\
S\left(p_{i}\right)=\left[\begin{array}{lll}
2.1618 & 2.3660 * 10^{-4} & 0.0014 \\
2.366 * 10^{-4} & 2.5208 * 10^{-8} & 1.5185 * 10^{-7} \\
0.0014 & 1.5185 * 10^{-7} & 9.1469 * 10^{-7}
\end{array}\right]
\end{gathered}
$$

$K_{\alpha}\left(p_{x}\right)=$

$\left[3.4753 * 10^{-7} \quad 7.5482 * 10^{-5} \quad 0.9984\right.$

$$
\begin{aligned}
& K_{\beta}\left(p_{x}\right) \\
& =\left[3.4754 * 10^{-7} \quad 1.3510 * 10^{-4} \quad 3.1594\right.
\end{aligned}
$$

$L\left(p_{x}\right)$

$S\left(p_{x}\right)=\left[\begin{array}{lll}7.926 * 10^{-23} & 4.619 * 10^{-16} & 1.531 * 10^{-11} \\ 4.619 * 10^{-16} & 2.283 * 10^{-9} & 7.117 * 10^{-5} \\ 1.531 * 10^{-11} & 7.117 * 10^{-5} & 2.1593\end{array}\right]$

\section{SIMULATION CONSEQUENCES \& RESULTS}

The dynamic reactions of the nation elements intake complicated ( $\left.p_{-} \mathrm{i}\right)$ and Turbine manage $\left(\mathrm{p}_{-} \mathrm{x}\right)$ for the 2 manipulate inputs VGT (B_2) and Fuelling (B_3) for every one of the instances are seemed in Fig's 3-10.

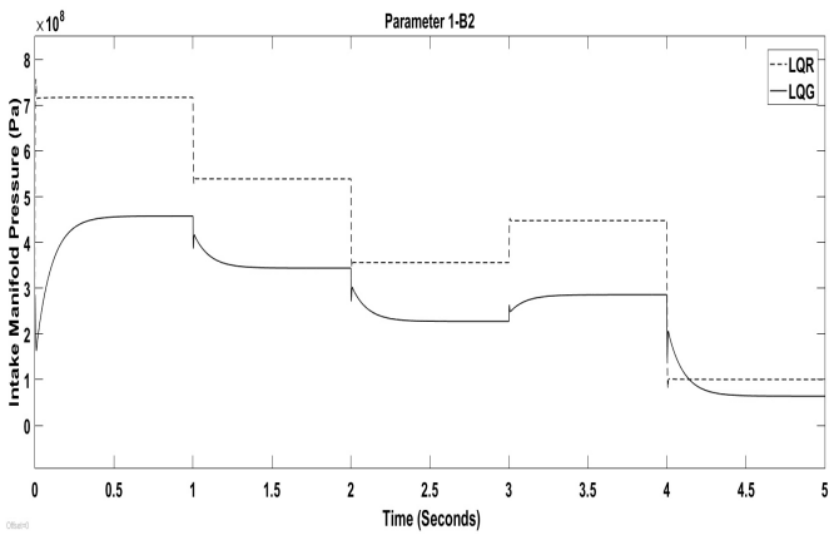

Figure 3: $p_{i}$ response of Case I

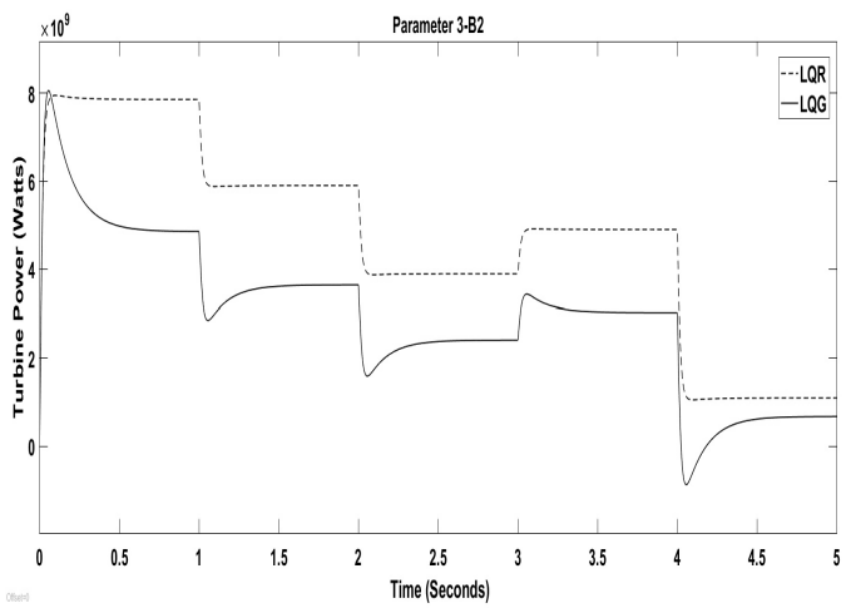

Figure 4: $p_{x}$ response of Case I

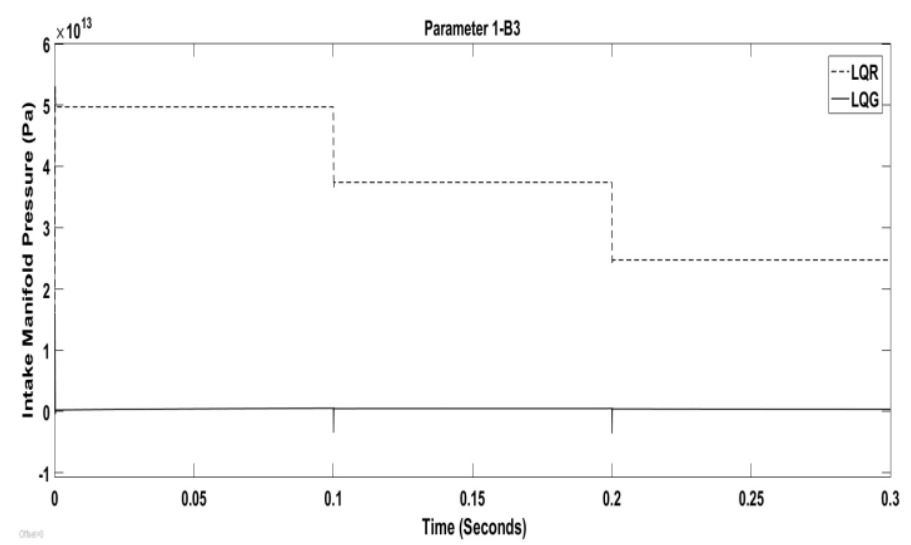

Figure 5: $p_{i}$ response of Case II 


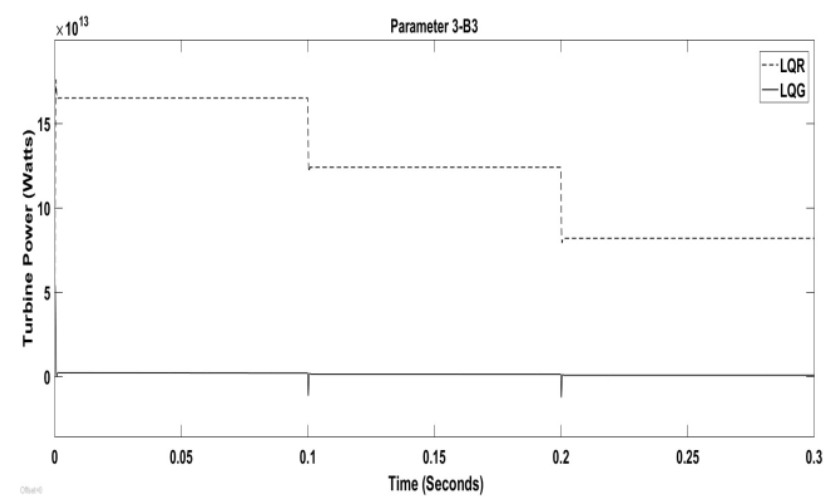

Figure 6: $p_{x}$ response of Case II

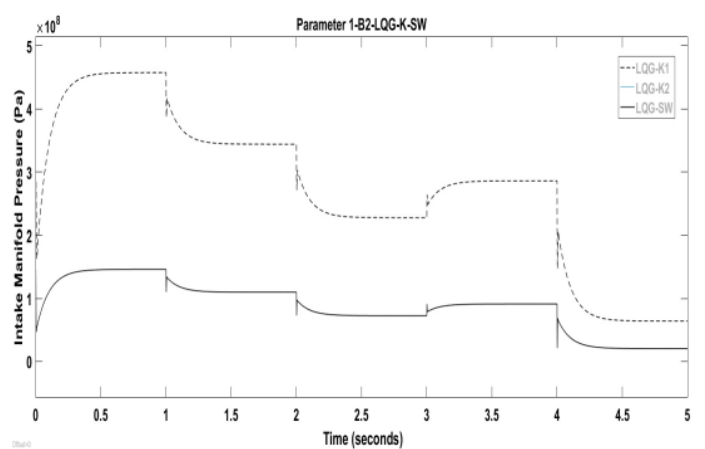

Figure 7: $p_{i}$ response of Case III

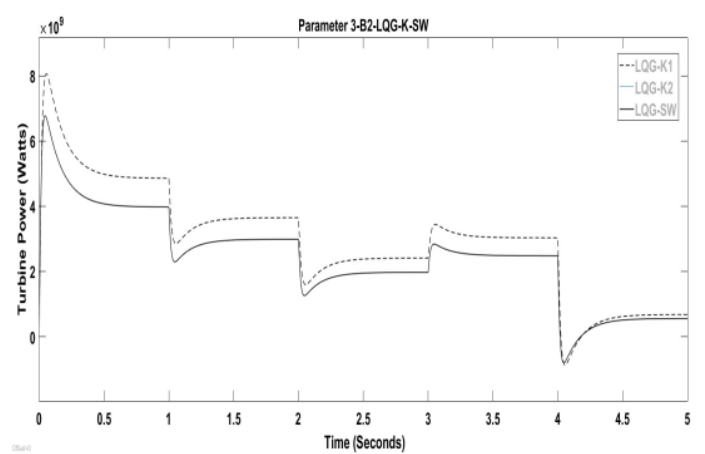

Figure 8: $p_{x}$ response of Case III

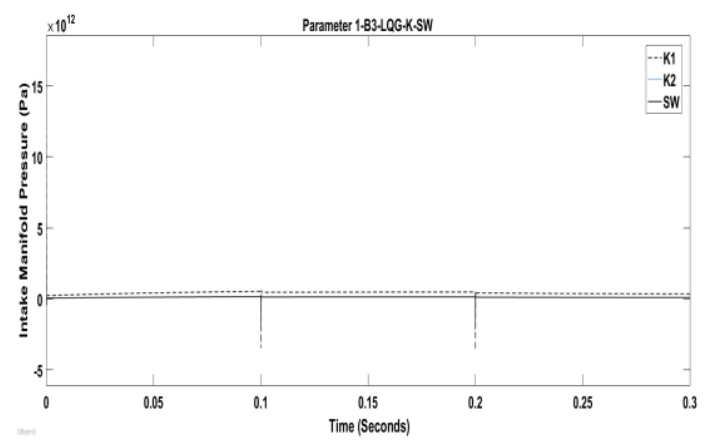

Figure 9: $p_{i}$ response of Case IV

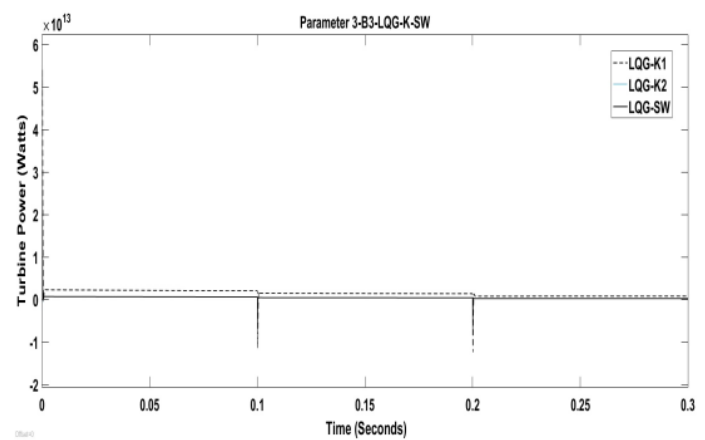

Figure 10: $\boldsymbol{p}_{x}$ response of Case IV

The reenactment consequences of case I (Fig. 3 and Fig. 4.) and Case II (Fig. 5 and Fig. 6) demonstrates the response of the 2 state elements ( $p_{-} i$ and $p_{-} x$ ) beneath the deterministic and unusual unsettling influences for the manage inputs VGT (B_2) and Fuelling (B_3). The deterministic unsettling affect is calulated as in LQG manage plan and the abnormal aggravation is appropriated with arbitrary signal with yield repeatable for a given speed with imply $=0$; difference $=$ four, speed $=0$.five and inspecting time $=0.1 \mathrm{sec}$. The pastime results uncovers that the LQG manage demonstrates the advanced exhibition as for damping and unfaltering state errors contrasted with the LQR manage techniques.

Case III and Case IV appear, the dynamic response of the exchanging among LQG controllers for the two manipulate inputs B_2 and B_3, wherein the criticism controllers will transfer as constant with the device of changing rule and the eyewitness gain L stays constant. The advanced replica effects indicates that the proposed exchanging criticism controller will change to the quality individual LQG controller.

\section{END}

within the current scenario the automobile cars are basically affected because of the unsettling impacts. consequently, on this paper the arbitrary and dweterministic clamors are carried out to air way elements and understood the use of LQR and LQG first-class controllers. four affiliation of trials are conveyed to demonstrate the viability of the proposed manipulate strategies. inside the first and $2 \mathrm{~d}$ arrangement of examinations, the LQR and LQG ideal controllers are deliberate with the aid of thinking about the unsettling influences for the kingdom elements $\mathrm{p} \_\mathrm{i}$ and $\mathrm{p} \_\mathrm{x}$ for the two manipulate inputs B_2 and B_3 and reproduction results uncovers that the LQG controller is better evaluation with LQR at the same time as the framework is uncovered to aggravations. basically, to demonstrate the adequacy of changing in price zero. 33 and fouth set of trials are conveyed to replace among LQG controllers for the 2 control B_2 and B_3, and undertaking results presume that the proposed converting manage will trade to the higher man or woman LQG manage.

\section{REFERENCES}

1. Mike Huang, "Low Complexity version Predictive manipulate of a Diesel Engine Airpath", Ph.D. Proposition, Aerospace Engineering, university of Michigan, 2016.

2. Javad Mohammadpour, Karolos Grigoriadis and Matthew Franchek, "LPV Decoupling and enter Shaping for manage of Diesel Engines, complaints of american manipulate conference, June 30-July 02, 2010, pp. $1477-1482$

3. Stephan Zentner, Erika Schafer, Gerald rapid, Christopher H Onder and Lino Guzzella, "A fell control structure for airpath manage of diesel cars", journal of vehicle Engineering, Vol. 228, trouble 7, 2014, pp. 799â€"817, DOI:10.1177/0954407013493617.

Published By:

Blue Eyes Intelligence Engineering

\& Sciences Publication 

OPTIMAL \& SWITCHING CONTROL TECHNIQUES

4. Dezong Zhao, Cunjia Liu and Richard Stobart, "Unequivocal version Predictive control broadcasting stay route of Turbocharged Diesel Engines", complaints of IEEE American automated manipulate Council, Loughborough college, 2013.

5. Giorgio Mancini , Jonas Asprion and Nicolã ${ }^{2}$ Cavina, "Dynamic Feedforward control of a Diesel Engine based on most reliable brief compensation Maps", Energies, Vol. 7, pp. 5400-5424, ISSN: 1996-1073, DOI:10.3390/en70854.

6. Fereidoon Shabaninia and Kazem Jafari, "utilising LQG/LTR premier control method to improve stability and overall performance of commercial gas Turbine device", global Scholarly research network ISRN Electronics, Vol.1, $2012 \quad$,pp. 1-8, DOI: $10.5402 / 2012 / 134580$

7. Mohamed Guermouche and Sofiane Ahmed Ali "Sliding mode manage for variable geometry turbocharged diesel cars", American control convention, Vol. 1, issue 6, pp. 584 - 588, 2014, DOI: 10.1109/ACC.2000.878967.

8. Peter Langthaler and Luigi del Re, "Prescient control of a Diesel Engine Air course", IEEE Transactions on control structures era, Vol. 15, difficulty three, 2014, pp. 449 456, DOI: 10.1109/TCST.2007.894638.

9. Zhijia Yang, "perfect Air and fuel-direction manipulate of a Diesel Engine", Ph.D. concept, branch of Aeronautical and car Engineering Loughborough college November 2014.

10. Jung M, "imply-esteem displaying and active manipulate of the air manner of a turbocharged diesel engineâ€• , Ph.D Dissertation, university of Cambridge, 2003.

11. B. D. O. Anderson, J. B. Moore, "best manipulate: Linear Quadratic techniques", new york: Dover guides, 2007.

12. L. Yathisha and S. P. Kulkarni, "perfect LQR changing approach for the development of STATCOM execution", complaints of the third worldwide conference on developments in facts, Telecommunication and Computing, the big apple: Springer, 2013, pp. 259 â $€ "$ 266.

13. S. P. Azad and R. Iravani, T. J. E, "Damping between territory motions depending on a version prescient control (MPC) HVDC strengthening controller", IEEE Transactions on electricity structures, 2013, Vol. 28, trouble 3, pp. 3174 â€" 3183.

14. P. Tripathy, S. C. Srivastava and S. N. Singh, "A partition by means of manner of-differencefilter primarily based calculation for estimation of generator rotor thing the usage of synchrophasor estimations", IEEE Transactions on Instrumentation and measurement, 2010, Vol. fifty nine, problem 6, pp. 1562 â€" 1570.

15. A. M. Yousef and M. Zahran, "progressed electricity framework stabilizer via utilizing LQG controller", Advances in electrical and pc Engineering, 2008, Vol. eight, issue 1, pp. 117 â€" 127.

16. J. L. Aravena and L. Devarakonda, "Execution pushed converting manage", IEEE worldwide Symposium on commercial Electronics, 2006, DOI 10.1109/ISIE.2006.295564.

17. L. Yathisha and S. P. Kulkarni, "software and examination of replacing control calculations for energy framework stabilizer", IEEE global convention on business Instrumentation and manage, Pune: IEEE, 2015, pp. 1300 â€" 1305.

18. L. Yathisha, ok. Davoodi and S. P. Kulkarni, "perfect converting control approach for UPFC for widespread scope of operating conditions in electricity framework", lawsuits of third Indian manipulate convention, Guwahati: IEEE, 2017, pp. 225 â€" 232.

19. L. Yathishai and S. P. Kulkarni, "LQR and LQG based totally best changing techniques for PSS and UPFC in power frameworks", control idea and generation, Springer magazine, Vol. 16, difficulty 1, pp. 1-13, 2018. 